\title{
SATELLITE BASED LAND SURFACE TEMPERATURES ALONG THE COASTAL MANDALS OF VISAKHAPATNAM DISTRICT, ANDHRA PRADESH, INDIA
}

\author{
B.Anandagajapathi Raju ${ }^{1}$, Ramdas.P ${ }^{2}$, K.Rambabu ${ }^{3}$, M.Subrahmanyam ${ }^{4}$ \\ ${ }^{1,2,3,4}$ Department of Geophysics, Andhra University, Visakhapatnam
}

\begin{abstract}
The Rapid development of any city leads to Changes in Land use Land cover pattern, these changes attribute to Changes in Land Surface Temperature (LST). The LST from Earth Observation satellites is essential factor in global climate change, vegetation growth and also in monitoring urban climate, understanding the environmental conditions necessary to sustain human life.The Present Study is carried out to derive the LST of Coastal Mandals of Visakhapatnam District, A.P. India by using Landsat 8 Optical Land Imager (OLI) of $30 \mathrm{~m}$ resolution and Thermal Infrared Sensors (TIR) data of $100 \mathrm{~m}$ resolution. The Spectral radiance was estimated using TIR band 10. Emissivity was derived with the help of NDVI. From the detailed analysis, identified that, the LST of the present study area is varying from $24.12^{\circ} \mathrm{C}$ to $37.74^{\circ} \mathrm{C}$ during the month of May 2016.
\end{abstract}

Keywords: LST, LSE, NDVI, OLI, TIR, Visakhapatnam.

\section{INTRODUCTION}

The Land Surface Temperature (LST) is the radiative skin temperature of ground (www.land.copernicus.eu/global/prduct/lst). LST is the temperature emitted by the surface and measured in Kelvin. Numerous researchers have done substantial work on LST. It was greatly affected by the increasing greenhouse gases in the atmosphere (Rajeswari A, et al, 2014). When the LST rise it causes environmental unbalance situation like melts in glacier, Vegetation, Climatic Condition of monsoon countries leading to unpredictable rainfall (Md.Shahid Latif, et, al, 2014). Knowledge of the LST provides information on the temporal and Spatial Variations of the Surface equilibrium state and is of fundamental importance in many applications .Satellite based land surface temperature measurements have a wide variety of applications including Climate Change, hydrological cycle, vegetation monitoring, urban climate and environmental studies, among others (H.Tang and Z-L, 2014, Zhao-Liang Li et al, 2012, Arnfield, 2003, Hansen et al., 2010, Kalma et al., 2008, Kogan, 2001, Su, 2002, Voogt and Oke, 2003, Weng, 2009 and Weng et al., 2004). Due to the strong heterogeneity of land surface characteristics such as vegetation, topography, and soil (Liu et al., 2006 and Neteler, 2010), LST changes rapidly in space as well as in time and an adequate characterization of LST distribution and its temporal evolution, therefore, requires measurements with detailed spatial and temporal sampling. Thermal Remote Sensing helps in study of the thermal characteristics of land surface (Md.Shahid Latif, et al, 2014). Developmental activities like Urbanization, industrialization etc., are taking place after State bifurcation and announcement of Smart city as Visakhapatnam of
Andhra Pradesh state, and its adjacent areas especially coastal mandals, this leads to changes in the thermal characteristics of land surface. In order to calculate the LST of coastal mandals of Visakhapatnam district, Andhra Pradesh, India Landsat-8 satellite images were used.

\section{STUDY AREA}

The entire coastal Mandals namely Payakaraopeta, Nakkapalli, S.Rayavaram, Rambilli, Atchutapuram, Paravada, Pedagantyada, Gajuwaka, Visakhapatnam (Urban \& Rural) and Bheemunipatnam of Visakhapatnam district, Andhra Pradesh, India (Fig.1) lies between $17.245^{\circ}$ to $18.521^{\circ} \mathrm{E}$ Latitude and $82.518^{\circ}$ to $83.521^{\circ} \mathrm{N}$ Longitudes.

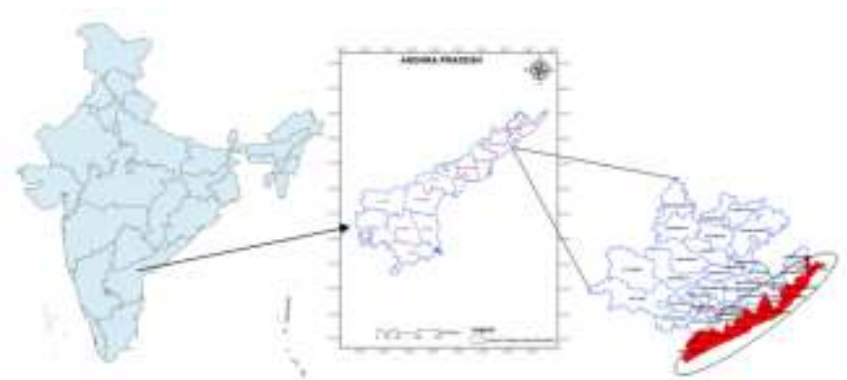

Fig.1 Study area map showing Coastal mandals of Visakhapatnm District, Andhra Pradesh, India.

\section{DATA SOURCE}

Acquired cloud free data of Path 141 and Row 048 of Landsat 8 TIRS (Thermal Infrared Sensor) Band 10 and OLI (Operational Land Imaginer) sensor Band (1-9) covering the Coastal Mandals of Visakhapatnam District, Andhra Pradesh, India of date 2nd, May, 2016 from www.earthexplorer.usgs.gov. 


\section{METHODOLOGY}

Numerous researchers have been used the Landsat 8 satellite images for retrieval of LST (Qihao Weng et al (2003), Rajeshwari et al (2014), Md. Shahid Latif (2014), Rosmini et al (2015), S.Zareie et al (2016), Suresh S et al (2016). The downloaded Landsat 8 images are processed, for calculating the Land Surface Emissivity, Normalized Difference Vegetation Index and Land Surface Temperatures by using the below mentioned formulas by using Arc GIS 10.1 and ERDAS IMAGINE 13 Software Packages. For calculating LST, we need to convert the OLI and TIRS band data to TOA spectral radiance using the radiance rescaling factors provided in the metadata file, and Conversion to At-Satellite Brightness Temperature.

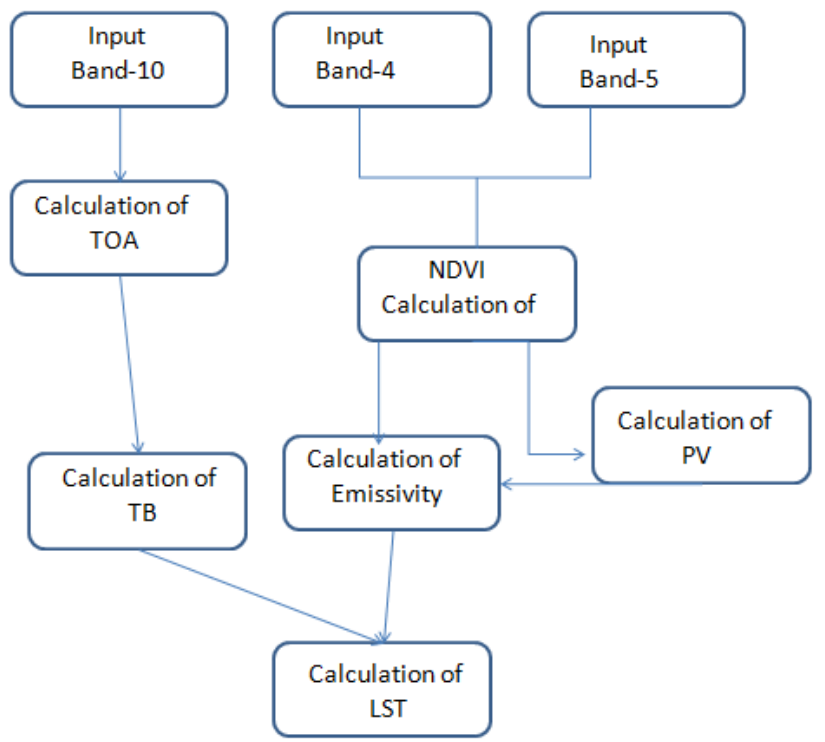

Flowchart for calculation of LST from Landsat-8 images

\section{Brightness Temperature}

Brightness temperature (TB) is the microwave radiation radiance traveling upward from the top of Earth's atmosphere. The next step is to convert the spectral radiance to at-satellite brightness temperature under the assumption of uniform emissivity. The conversion Formula is

$\mathrm{TB}=\mathrm{K}_{2} / \ln \left[\left[\mathrm{K}_{1} / \mathrm{L} \lambda\right]+1\right]$

Where,

$\mathrm{TB}=$ Effective At-Satellite temperature in $\mathrm{K}$,

$\mathrm{L} \lambda=$ Spectral radiance in $\mathrm{W} /\left(\mathrm{m}^{2} *\right.$ ster* $\left.\mu \mathrm{m}\right)$; and $\mathrm{K} 2$ and

$\mathrm{K} 1$ are pre-launch calibration constants (For

Landsat 8 for Band 10, $\mathrm{K}_{1}=1321.08$; K2=777.89 from Meta data)

\section{Top of Atmospheric Spectral Radiance}

The value of Top of Atmospheric (TOA) spectral radiance (L $\lambda$ ) was determined by using the below formula.

$\mathrm{L} \lambda=\mathrm{ML} * \mathrm{Qcal}+\mathrm{AL}$
Where,

$\mathrm{L} \lambda=$ Top of Atmospheric Radiance in watts/ (m2* $\left.\operatorname{srad}^{*} \mu \mathrm{m}\right)$ $\mathrm{ML}=$ Band specific multiplicative rescaling factor (radiance_mult_band_10/11, from Meta data file)

Qcal $=$ band $10 / 11$ image .

$\mathrm{AL}=$ Band specific additive rescaling factor (radiance_add_band_10/11, from Meta data file)

\section{Land Surface Emissivity (e)}

To derive Land Surface Emissivity, the proportion of Vegetation (PV) is required, extracted bands red and Near Infrared and generated NDVI map and by making use of NDVIs (Soil), NDVIv (Vegetation) values (Ugur Avdan and Gordana Jovanovska,2016), calculated PV, and calculated the Land Surface Emissivity (e) by using equation (5) in Arc GIS10.1.

NDVI $=$ NIR-RED/NIR+RED

For Landsat 8 NDVI= Band 5- Band 4/ Band 5+ Band 4

$\mathrm{PV}=(\mathrm{NDVI}-\mathrm{NDVIs} / \mathrm{NDVIV}-\mathrm{NDVIs})^{2}$

$\mathrm{PV}=$ Proportion of vegetation

$\mathrm{e}=0.004 \mathrm{PV}+0.986$

The concept of NDVI has been used extensively to measure vegetation cover characteristics, crop assessment studies, and the vegetation indices are mathematic combination of various bands, it can vary from -1 to +1 depending on the relative value of red and IR reflectance (George Joseph,2005).Extracted the required bands like Red band, Near Infra Red band, prepared NDVI (Normalized Deficiency Vegetation Index) by using the below mentioned formula in the ERDAS (Earth Resources Data Analysis System) 13.

\section{Land Surface Temperature (LST)}

Calculated the LST from Brightness Temperature (TB) equation (1) and Land Surface Emissivity (e) equation (5) by using the below formula.

$\mathrm{LST}=\mathrm{BT} / 1+\mathrm{W} *(\mathrm{BT} / \mathrm{p}) * \ln (\mathrm{e})$

Where:

BT $=$ At - Satellite temperature

$\mathrm{W}=$ Wavelength of emitted radiance $(11.5 \mu \mathrm{m})$

$\mathrm{P}=\mathrm{h} * \mathrm{c} / \mathrm{s}\left(1.438 * 10^{\wedge}-2 \mathrm{~m} \mathrm{~K}\right)$

$\mathrm{h}=$ Planck's constant $\left(6.626 * 10^{\wedge}-34 \mathrm{Js}\right)$

$\mathrm{s}=$ Boltzman Constant $\left(1.38 * 10^{\wedge}-23 \mathrm{~J} / \mathrm{K}\right)$

$\mathrm{c}=$ velocity of light $\left(2.998 * 10^{\wedge} 8 \mathrm{~m} / \mathrm{s}\right)$

$\mathrm{p}=14380$

\section{ANALYSIS AND DISCUSSION}

The NDVI Map (Fig.2) clearly shows the range between 0.151 to 0.5300 in the present study area. Most of the Visakhapatnam City area had negative NDVI values and the hilly regions had highest NDVI values. 


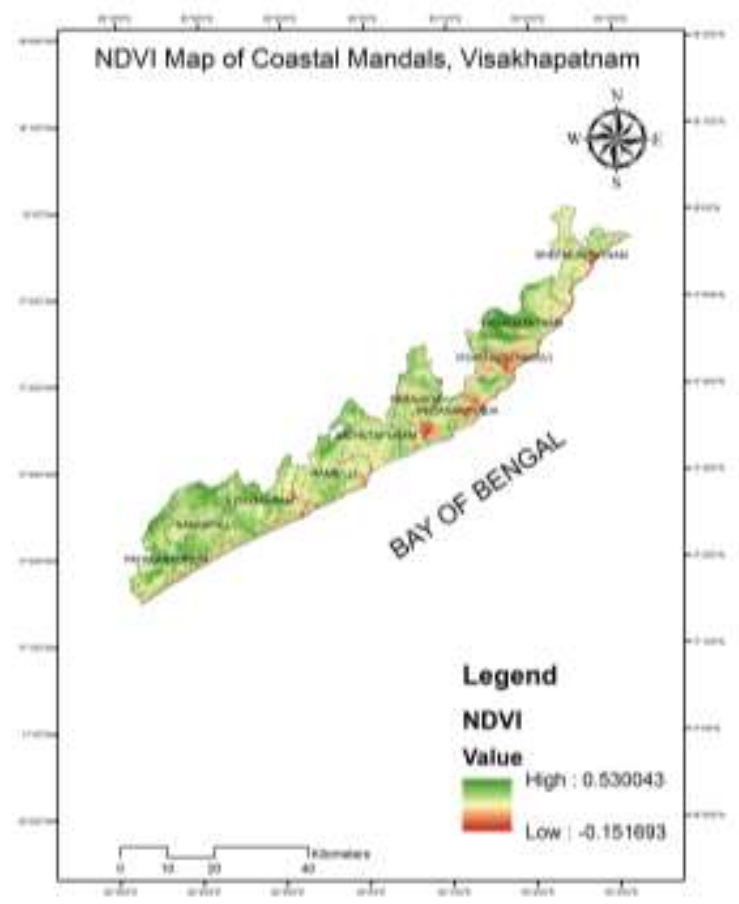

Fig.2. NDVI map of Coastal Mandals of Visakhapatnam District, A.P, India

The Proportion of Vegetation (PV) is essential for determination of Land Surface Emissivity(e), The PV is derived from the NDVI, NDVIv and NDVIs values as shown in the equation (4), then ' $\mathrm{e}$ ' is derived from the equation (5). The emissivity values in the present study area ranging from 0.986 to 0.991 (Fig.3) from the results, the LSE of Water bodies are ranged between 0.988 to 0.990 , Built-up area was 0.9863 to0.9866, Agriculture areas was 0.9872 to 0.9875 .

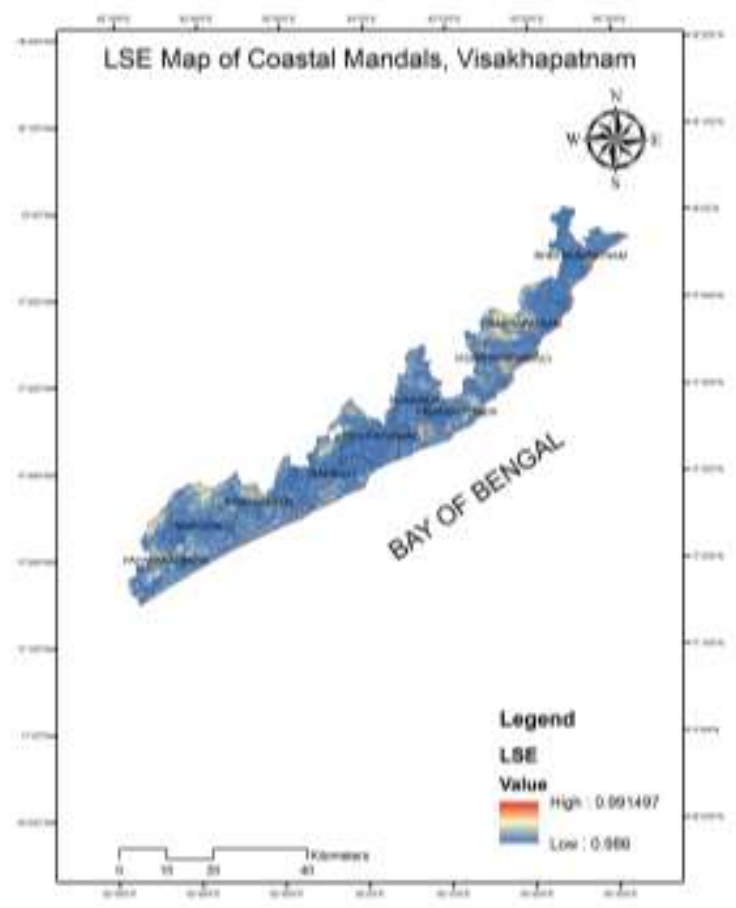

Fig.3 Land Surface Emissivity of Coastal Mandals of Visakahapatnam District,A.P.India.
From the LST map, (Fig4) the present study area experienced the Land Surface Temperatures ranging from 24.123 to $37.745^{\circ}$ C.South and South west part mandals like Payakaraopeta, Nakkapalli, S.Rayavaram and Rambilli shows the lowest LST. The north of the study area especially northern part of Bheemili, Visakhapatnam (Rural \& Urban) mandals shows highest LST ranging from 32.36 to $37.45^{\circ} \mathrm{C}$.

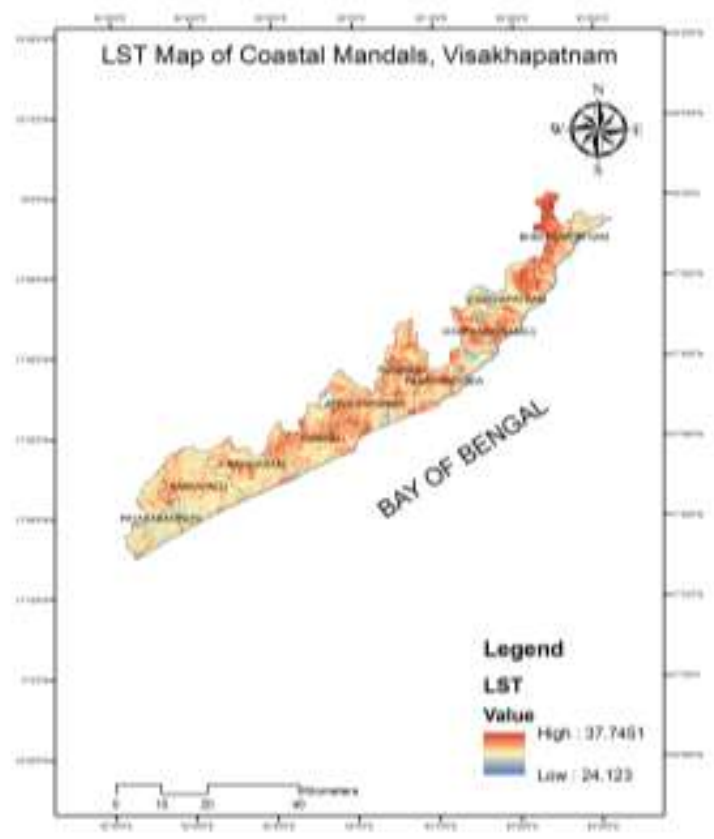

Fig.4. Land Surface Temperatures of Coastal Mandals of Visakahapatnam District, A.P.India.

\section{CONCLUSION}

From the detailed analysis of LST, identified that, the LST in Agricultural areas are around $30.02^{\circ} \mathrm{C}$, in urban areas $32.84^{\circ} \mathrm{C}$, and the hilly regions are around $27.57{ }^{\circ} \mathrm{C}$ in the Coastal mandals of Visakhapatnam District, Andhra Pradesh, India. And the urban areas are experienced high LST when compared with Agricultural and hilly terrains. These types of studies especially continuous monitoring of Land Surface Temperatures are very much useful for planning of Land use Land cover utilization for effective management of ecological balance.

\section{REFERENCES}

[1] Arnfield A. J. Two decades of urban climate research: a review of turbulence, exchanges of energy and water, and the urban heat island. Int $\mathbf{J}$ of Climatol, Vol.23, pp. $1-26.2003$

[2] Daniel Hillel "Advances in Irrigation",Vol.No.2: ISBN: 0-12-024302-4, ISSN:0275-7915, 1983 Academic Press, Inc, New York.

[3] Definition of LST from http:/www.land.copernicus.eu/global/prduct/lst.

[4] Felix Kogan and Wei Guo 2011 "Use of Satellite and In-Situ Data to Improve Sustainability, NATO Science for Peace and Security Series C". "Early Detection and Monitoring Droughts from NOAA Environmental 
Satellites": Environmental Security, DOI 10.1007/97890-481-9618-0_2.

[5] George Joseph " Fundamentals of Remote Sensing” Second Edition,ISBN:978 817371 5358, 2005

[6] H.Tang and Z-L,Li, Quantitative Remote Sensing in Thermal Infrared; theory and Applications, Springer Remote Sensing / Photogrammaetry, DOI.10.1007/9783-642-42027-6_5 , Springer-Verlag Berlin Heidelberg,2014.

[7] J.A.Voogt and T.R.Oke, "Thermal Remote Sensing of Urban climates" Journal of Remote Sensing of Environment. Vol. 86 .pp.370-384.2002.

[8] J.etse D.Kalma, et al, "Estimating Land Surface Evaporation: A Review of Methods Using Remotely Sensed Surface Temperature Data" journal of Surveys in Geophysics, Volume29, Issue 4,pp:421-469.2008.

[9] J.Hansen, R.Ruedy, M.Sato and K.Lo "Global Surface Temperature change" J. American Geophysical Union, 8755-1209/10/2010/RG000345.2010.

[10] Kogan FN "Operational space technology for global vegetation assessments". Bull Am Meteor Soc Vol.82.Issue 9.,pp:1949-1964.2001.

[11] Landsat8 imageries from www.earthexplorer.usgs.gov.

[12] Markus Neteler,2010 "Estimating Daily Land Surface Temperatures in Mountainous Environments by Reconstructed MODIS LST Data" Journal of Remote Sensing, Remote Sens. Vol.2,pp: 333-351;2010.

[13] Md.Rejaur Rahman et al "Plan Plus", Volume 1 No2, pp:1-12,2004.

[14]Md Shahid Latif et al, Land Surface Temperature Retrival of Landsat-8 Data Using Split Window Algorithm- A Case Study of Ranchi District , International Journal of Engineering Development and Research, Vol.No.2, Issue4. 2014

[15]Qihao Weng "Thermal infrared remote sensing for urban climate and environmental studies: Methods, applications, and trends", ISPRS Journal of Photogrammetry and Remote Sensing, Vol.64. pp: 335344, 2009.

[16]Qihao Weng et al "Estimation of Land Surface Temperature - Vegetation abundance relationship for urban heat island studies". J. Remote Sensing of Environment Vol.89,pp:467-483. 2003.

[17] Rajeshwari.A and N. Mani, "Estimation of land surface temperature of dindigul district using landsat 8 data," International Journal of Research in Engineering and Technology, vol. 3, no. 5, pp. 122-126, 2014.

[18] Rosmini Maru et al (2015) “ Trend Analysis of Urban Heat Island Phenomenon in the city of Makassar, South Sulawesi, Indonesia using Landsat". Asian Journal of Applied Sciences, ISSN: 2321-0893, Volume-03, Issue05.

[19] Shunlin Liang "Quantitative Remote Sensing of Land Surface" ISBN:978-0-471-28166-5. 2003.

[20] Suresh s et al " Estimation of Land Surface Temperature of High Range Mountain Landscape of Devikulam Taluk using Landsta 8 data". IJRET, Vol.5, Issue: 01 eISSN;2319-1163/pISSN:2321-7308. 2016.

[21] S.Zareie et al "Derivation of land surface temperature from Landsat Thematic Mapper (TM) sensor data and analyzing relation between land use changes and surface temperature. Solid Earth Discuss., doi:10.5194/se-2016-22, 2016.

[22] Ugur Avdan and Gordana Jovanovska. Algorithm for Automated Mapping of Land Surface Temperature Using LANDSAT 8 Satellite Data, Journal of Sensors, Volume 2016 (2016), Article ID 1480307, 8 pages

[23]Zhao-Liangli et al, "Satellite-derived land surface temperature: Current status and perspectives" Journal of Remote Sensing of Environment, Vol.No.131, Pages 14-37, April, 2013,

[24]Z.Su, "The Surface Energy Balance System (SEBS) for estimation of turbulent heat fluxes" Journal of Hydrology and Earth System Sciences, Vol.6, No1,pp. 85-99.2002. 